\title{
An Extended Model of Behavioural Process in Consumer Decision Making
}

\author{
Nagasimha Balakrishna Kanagal ${ }^{1}$ \\ ${ }^{1}$ Indian Institute of Management, Bangalore, India \\ Correspondence: Nagasimha Balakrishna Kanagal, Indian Institute of Management, Bannerghatta Road, \\ Bangalore, 560076, India. Tel: 91-80-26993185. E-mail: kanagal@iimb.ernet.in
}

Received: June 2, 2016 Accepted: July 6, $2016 \quad$ Online Published: July 27, 2016

doi:10.5539/ijms.v8n4p87 URL: http://dx.doi.org/10.5539/ijms.v8n4p87

\begin{abstract}
The stimulus response model of consumer behaviour is useful to understand the buying behaviour of individual consumers in the context of individuals buying consumer products. An extended stimulus-response model of behavioural processes in consumer decision making is proposed that serves to integrate the influences and interlinkages of buyer psychology, various buyer characteristics, and the impact of the buyer decision process on consumer decision making. The model proposes that the behavioural process of consumer decision making be as a result of the interaction of three aspects of individual buyer behaviour: communication sensitivity; enculturated individuality; and rational / economic decision making. The paper addresses the flip side of the consumer decision making process in terms of the five stages of decision making from need recognition to post-purchase satisfaction. An aggregate level framework of behavioural process in consumer decision making has been provided, that could lead to a richer analysis of micro level factors and relationships influencing consumer decision behaviour.
\end{abstract}

Keywords: communication sensitivity, enculturated individuality, rational / economic decision making, behavioural process, consumer decision making

\section{Introduction}

The stimulus response model (Kotler, 1997) of consumer behaviour is useful to understand the buying behaviour of individual consumers in the context of individuals buying consumer products. The model succinctly puts forward that individual consumers are exposed to marketing stimuli such as product, price, place, and promotion; consumers are also exposed to other stimuli in the marketing environment that includes economic, technological, political and cultural aspects. The buyer's mental processes is visualized as a black box and the observations are of buyer decisions that include product choice, brand choice, dealer choice, purchase quantity, and purchase timing. Figure 1, given below depicts the stimulus-response model.

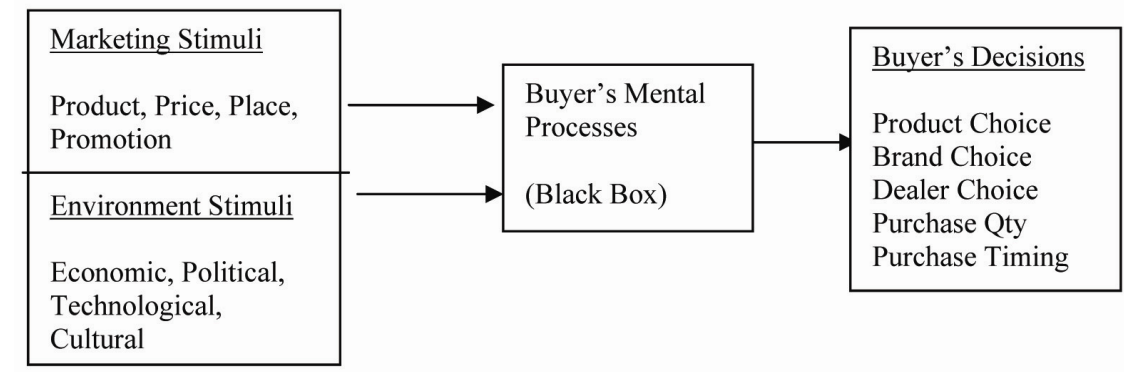

Figure 1. The basic stimulus-response model (Kotler, 1997)

\section{Method}

The paper lays out the extant framework of the stimulus response model, and conceptualizes a model of behavioural process in consumer decision making based on the principle of separating the buyer characteristics 
and buyer psychology factors into independent and dependent factors giving due regard to the buyer decision process and buyer decisions. Constituents of the buyer's mental processes are conceptualized. The research design is guided by the purpose of research for decision making; is qualitative and exploratory; and using conceptualization attempts to understand the broad nature of relationships among variables, components of a problem / phenomena of the behavioural process in consumer decision making.

\section{Extant Framework of Buyer's Mental Processes in the Stimulus-Response Model at the Overview Level}

The buyer's mental processes or the black-box of the stimulus response model is broadly categorized into three areas (Kotler \& Keller, 2016): (i) buyer psychology that include factors that include motivation, perception, learning and memory; (ii) buyer characteristics such as social, personal, psychological and cultural factors that influence buyer's behaviour; (iii) the buyer goes through a decision making process that is modeled as a five stage process consisting of: problem recognition, information search, evaluation of alternatives, purchase decision, and post purchase behaviour. Figure 2 given below depicts the black box of the buyer's mental processes.

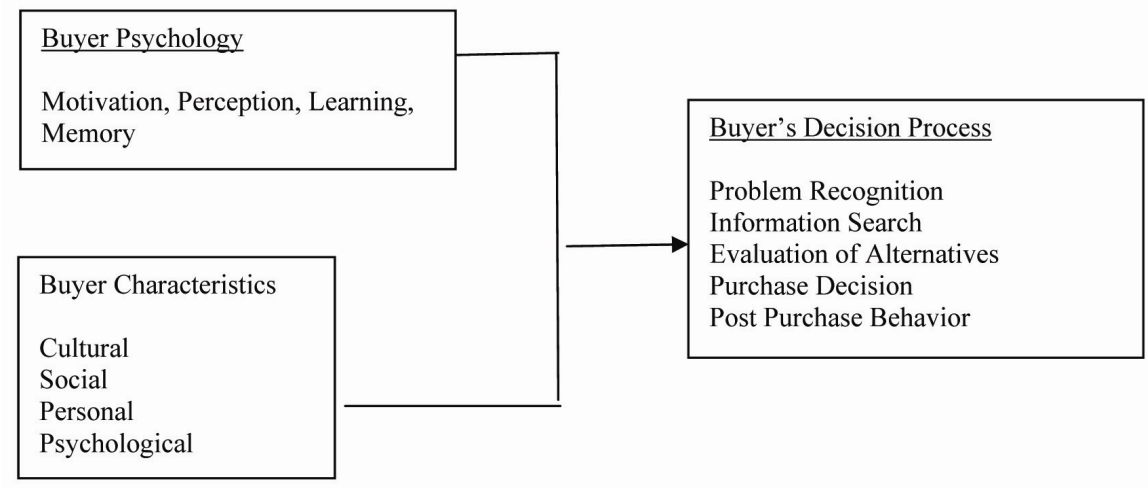

Figure 2. Extant framework for buyer's mental processes (Black Box) at overview levels (Kotler \& Keller, 2016)

\section{Extension of the Stimulus-Response Model: A Model of Behavioural Process in Consumer Decision Making}

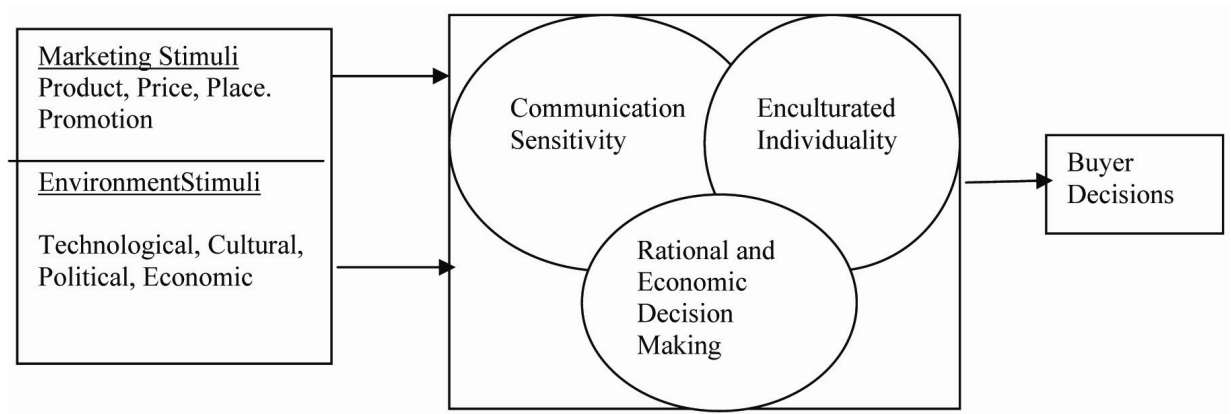

Figure 3. Proposed model of behavioural process in consumer decision-making

A model of behavioural process in consumer decision making is proposed that serves to integrate the influences and interlinkages of buyer psychology, various buyer characteristics, and the impact of the buyer decision process on consumer decision making. Factors that include age, life cycle are categorized as independent factors that influence buyer behaviour; whereas factors that include selectivity, personality are endogenously determined and in turn directly influence buyer behaviour. The extended stimulus-response model is depicted in Figure 3.

The model of behavioural process of consumer decision making proposes that the behavioural process of consumer decision making be as a result of the interaction of three aspects of individual buyer behaviour: (i) communication sensitivity: this is the sensitivity of the consumer to market communication; (ii) enculturated individuality: an individuality for purchase decision making that develops after strong exposure to a particular 
culture; (iii) rational and economic decision making: consumers are rational in their decision making of products and seek to maximize utility. This model of behavioural process in consumer decision making is further discussed in detail below.

\subsection{Communication Sensitivity}

The consumer is sensitive to two forms of communication: (a) within market communication; (b) firm to market communication.

\subsubsection{Within Market Communication}

This is also called self-referencing. Usage experiences of consumers who have bought the products/brands under consideration is the independent factor; word-of-mouth gets endogenously determined and is the means of communication within the market place. Word-of-mouth can be visualized to diffuse in the market place. Word-of-mouth is a very important influence especially for those consumers who are buying the product for the first time; it is also useful for new technology consumer products that cannot be assessed prima-facie and hence poses a risk to consumers. Negative word-of-mouth is very likely to restrain consumers from furthering their decision making process.

\subsubsection{Firm to Market Communication}

The below model in Figure 4 clearly delineates the relationship of the consumer with the external communication from firm to market. The independent factors are the communication messages via the communication vehicles chosen by the firm. These may include the print media, audio, TV, Internet / social media, Point of Purchase (POP) material, hoarding / kiosks. After a process of interaction of the consumer with the communication (4.1.2.1 below), a set of factors are endogenously determined that directly influence the way the consumer thinks and decides about his / her purchases. These dependent factors include selectivity, involvement, persuasion and learning.

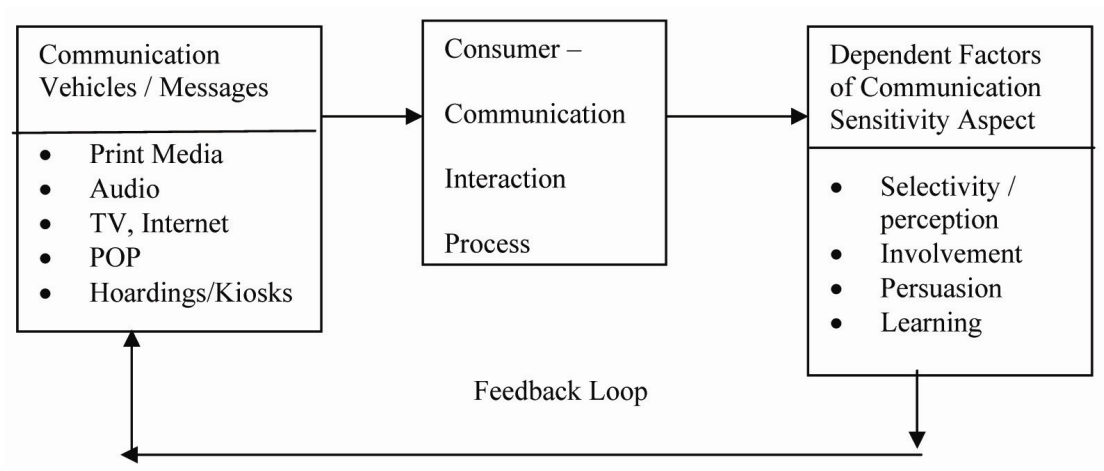

Figure 4. Firm to market communication sensitivity aspect of behavioural process of consumer decision making

\subsubsection{Consumer-Communication Interaction Process}

The interaction of the consumer with the communication messages via the communication vehicles takes place at both cognitive and affective levels.

At the cognitive level, there is a "need-use-gratification" paradigm that is likely to operate. Consumers have needs of seeking information for purchase. Further they may have other uses of the firm-to-market communication. Such uses could be diversion for consumers, surveillance or news value, value reinforcement, and source of information for personal discussions. For example, a consumer could hold a belief that watching the cable channel "CNN", gives him / her an edge in world affairs during his job interview or during his personal discussion with his peers. If and when this occurs, gratification is obtained. Gratification occurs when beliefs are reinforced after evaluation. Gratification on need-use in the communication process is likely to have a positive influence on selectivity, involvement, persuasion, and learning.

At the affective level, it is likely that the consumer is going through a process of Arousal-Mood-Media choice. Let us consider the television medium. It is possible that consumers choose media options (such as TV channels) with many different considerations (including situational considerations) other than use-gratification. In the process of having chosen a particular media option the consumer may experience different states of arousal as a 
consequence. The arousal state due to the program content (or entertainment content) of-say-a particular TV channel is going to influence the mood state. Such arousal-mood states not only influence choice of program content and consequently type of commercial content, but also the dependent factors of selectivity, involvement, persuasion, and learning.

Apart from the cognitive and affective processes of consumer interaction with the communication vehicles / messages, the consumer is also affected by the brand building activities of the marketer through symbols, brand associations portrayed through the medium of communication. Such an influence of brand building also influences the dependent factors of selectivity, involvement, persuasion and learning. From among the media vehicles in the market, television is most important. The other vehicles are Internet / social media, POP, English and Vernacular Magazines, Press Ads, Hoardings, Cinema Ads, and Kiosks.

\subsubsection{Dependent Factors of Communication Sensitivity Aspect}

Selectivity, involvement, persuasion and learning are four major consumer activities that get influenced as a result of consumer interaction with the external communication from firm to the market. Selectivity applies to perception formation that occurs in the evaluation of alternatives stage just before the consumer forms or modifies his / her preferences. This leads to selectivity of three kinds, which is well known - selective attention, selective distortion and selective retention. The level of involvement proposed by Krugman $(1965,1966)$ initially in the context of inferences of limited effects model, is another determined /dependent factor. For low involvement products, a peripheral route of persuasion may be suitable such as celebrity endorsements; it may enable gain awareness and liking of the consumer. For high involvement products, a central route of persuasion with rational and persuasive communication may be required. High involvement products could also use the peripheral route of persuasion depending on the context. Low involvement communication could be symbolic, repetitive advertisements while high involvement communications needs to be persuasive. Learning is induced by internal drives, but is influenced by cues, stimuli, and reinforcement of the communication environment.

\subsection{Enculturated Individuality}

Enculturated individuality refers to individuality for purchase decision making that develops after strong exposure to a particular culture. Cultural and social factors are mainly decided by the market-society and business environment at large and are as such independent factors. Similarly personal factors that include age, life cycle stage, occupation and economic circumstances are exogenous to the behavioural process of decision making. The sub-model in Figure 5 delineates the interlinkages for the enculturated individuality aspect.

However, these sets of cultural, social, and personal factors that influence the enculturation process of the individual in a business environment and market-society could undergo a process of change over time. The endogenous factors of the enculturated individuality aspect that directly influence the behavioural process of the consumer are personality and self-concept, life style, and motivation; these could undergo a change due to the influence of the independent factors apart from a gradual change due to the change of the market-society and business environment. Memory in turn moderates the endogenous factors of personality and self-concept, lifestyle, and motivation.

For example, the actual self-concept of a consumer (how he /she views herself), could be influenced by his / her economic circumstances, occupation, lifecycle stage, and family. The others self-concept of a consumer (how he / she thinks others see him / her; also called looking glass self) could be influenced by reference groups, roles / status, and social class. Activities, interests, and opinions of a consumer as manifested in a lifestyle are also to a large extent determined. Motives for buying, motives driving needs and wants could be well shaped by an acculturation process that has lasted a lifetime.

\subsection{Role of Beliefs / Values and Attitudes in the Behavioural Process of Consumer Decision Making}

Consumers acquire their beliefs and attitudes through a process of learning and usage of the products and services under consideration. Beliefs and attitudes have a long-term predisposition that gets modified with the experience of interaction and usage. Beliefs / values and attitudes are heavily influenced by the market-society and business environment around the consumer and in turn moderate the behavioural interaction of the consumer decision making process. That is to say, the perception and processing of the market stimuli and other environmental stimuli is influenced by the beliefs / values and attitudes developed over time. Beliefs / Values are shaped by the stimuli and the behavioural interaction of communication sensitivity, enculturated individuality, rational and economic decision making. 


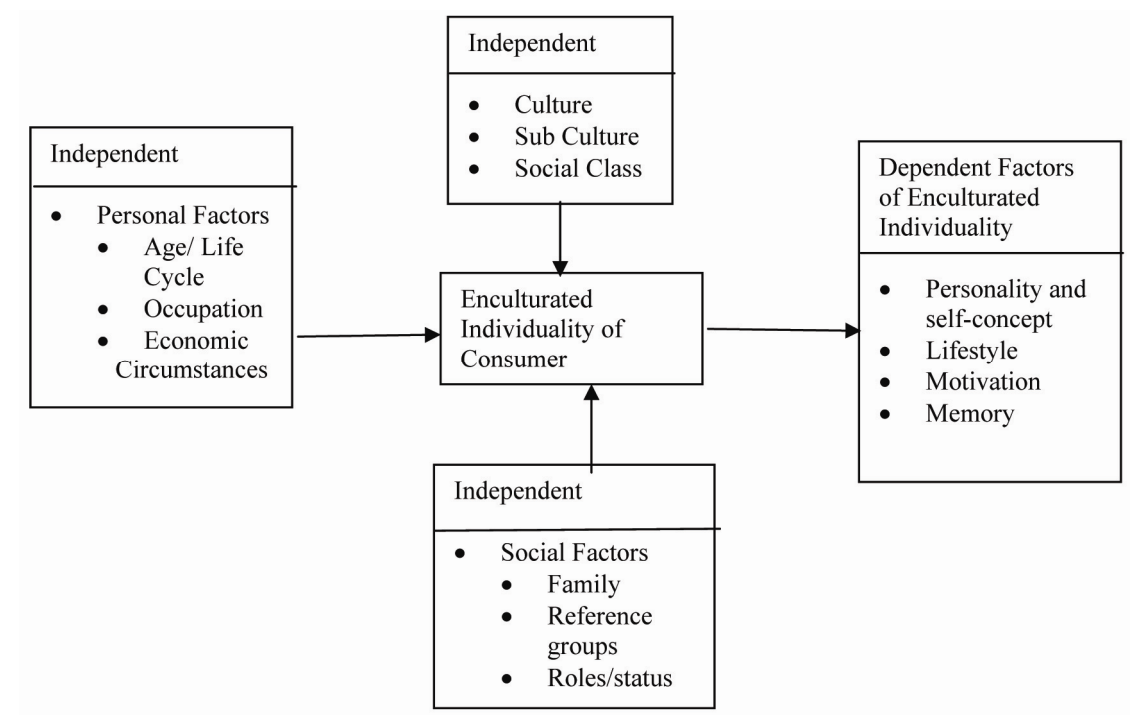

Figure 5. Enculturated individuality aspect of behavioural process of consumer decision making

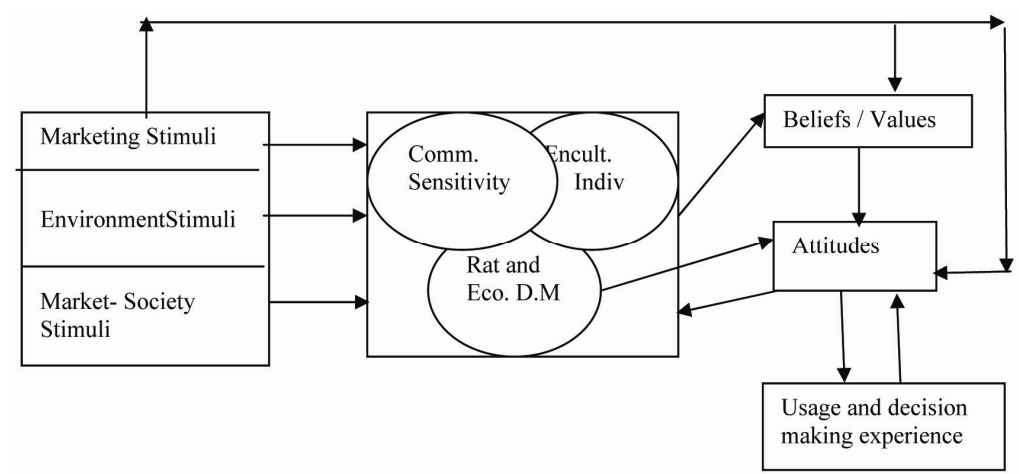

Figure 6. Interaction of beliefs / values and attitudes in the behavioural process of consumer decision making

Beliefs / values in turn influence attitudes; attitudes are also influenced by marketing stimuli, environment / society stimuli, experience of usage and past decision making, and by the rational and economic decision making aspect of the individual consumer. Attitudes in turn shape or influence the behavioural interaction of the consumer decision process. These interlinkages are depicted in the model in Figure 6 below.

\subsection{Rational and Economic Decision Making}

The rational and economic decision making process serves to maximize utility for the consumption basket at the least cost. The process gives due regards to constraints of the individual (e.g., he / she cannot access a distant store in a given time), situational constraints (need more ketchup as quite a few children have come home), budget constraints (there are category budgets and overall budgets). The endogenous factors of the communication sensitivity aspect and enculturated individuality aspect influence and get influenced by the rational and economic decision making activity. Though individual action does not change market stimuli, firms take decisions on their marketing variables based on aggregate level consumer response.

The consumer after the decision making experiences post purchase feelings. Such feelings can be explained by the dissonance theory or / and the contrast theory. In the dissonance approach, the consumer tries to rationalize his purchase to minimize the dissonance (e.g., a car). 


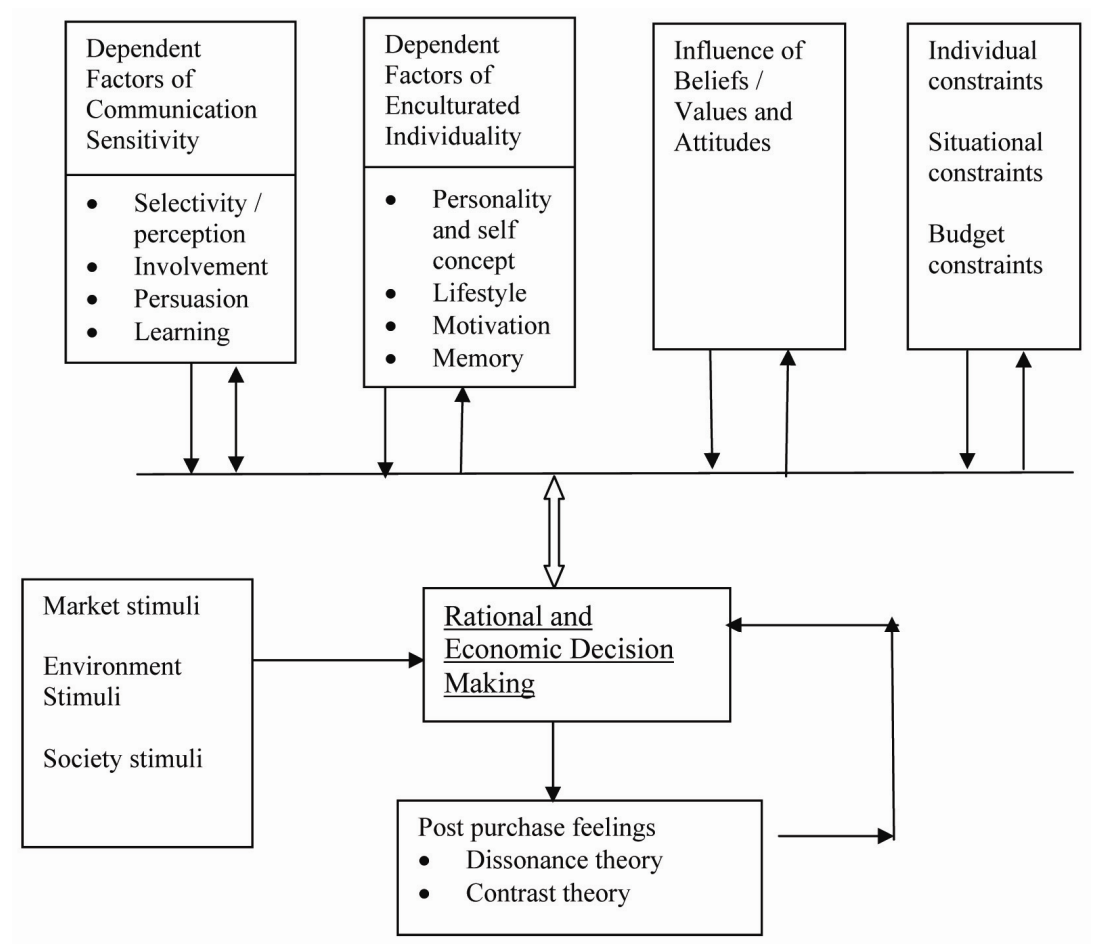

Figure 7. Behavioural interlinkages for the rational and economic decision making aspect

In the contrast theory approach the consumer regret increases over time and he seeks to avoid the purchase he / she made in the future. The model in Figure 7 above depicts these interlinkages for the rational and economic decision making.

The outcome decisions of the rational and economic decision making process can be broadly categorized as: (i) what to buy (basket of goods decision); (ii) where to buy (store choice); (iii) which brands to buy (brand choice); (iv) how much to buy (purchase quantity); and (v) how often to buy (purchase timing).

Before exhibiting a purchase behaviour, the consumer is likely to have started with brands from an awareness / evoked set, that has been filtered down to a consideration set. The consumer would then have formed the choice set (set of strong contenders) and made the purchase. The consumer is likely to have gone through the five stage decision making process of problem recognition, information search, evaluation of alternatives, purchase decision and post purchase feelings in varying degrees depending on whether it was routine buy, limited problem solving or extensive problem solving. The purchase process would have required the buyer to develop a purchase preference for a product and then develop purchase intention for specific brands before exhibiting purchase behaviour.

\section{Discussion}

Understanding consumer response to marketing decision variables is a significant area of examination. The market-society and business environment also transfer stimuli to the consumer. Classically response to marketing decision variables is studied at the individual level through brand choice models, and at the aggregate level of market data through econometric models of market share and sales. However, for appropriate modelling efforts, a rich understanding of the consumer's response to market stimuli will prove useful. The model depicts that the behavioural process of consumer decision making is an interaction of the communication sensitivity of the consumer to stimuli, the enculturated individuality, and the rational decision characteristics of the consumer. The paper thus addresses the flip side of the consumer decision making process in terms of the five stages of decision making from need recognition to post-purchase satisfaction. The model thus enables a richer scope for aggregate examination of the buyer characteristics and factors influencing decision behaviour. There is delineation into independent and dependent factors with the interlinkages of dependent factors among themselves and to decision process examined.

The dependent factors of the consumer decision making process include selectivity, involvement, persuasion, 
learning, personality and life concept, lifestyle, motivation, memory, beliefs, values, attitudes, individual constraints, situational constraints, budget constraints. As such the black box between the market stimuli and the consumer response has been delineated to be a rational and economic decision making process that is moderated by one or more of these dependent factors, which in turn are influenced by independent factors that include communication messages, social factors, cultural factors, personal factors, and situational factors. Surely, it is likely that some of these factors may stand modified in specific contexts and other aspects factored in. The role of beliefs/ values and attitudes is as a moderator to this behavioural process in consumer decision making.

An aggregate level framework to behavioural process in consumer decision making has been provided, that could lead to a richer analysis of micro level factors and relationships.

\section{References}

Bettman, J. R., Johnson, E. J., \& Payne, J. W. (1991). Consumer decision making. In T. J. Robertson \& H. H. Kassarjian (Eds.), Handbook of Consumer Behaviour. New Jersey: Prentice Hall.

Fletcher, K. (1987). Communication and the nature of consumer decision processes. Marketing Intelligence and Planning, 5(3), 20-26. http://dx.doi.org/10.1108/eb045752

Horton, R. L. (1979). Some relations between personality and consumer decision-making. Journal of Marketing Research, 16(2), 233-246. http://dx.doi.org/10.2307/3150687

Kotler, P. (1997). Marketing Management: Analysis, Planning, Implementation and Control (9th ed.). India: Prentice Hall.

Kotler, P., \& Keller, K. L. (2016). Marketing Management. India: Pearson.

Krugman, H. E (1965). The impact of television advertising: Learning without involvement. Public Opinion Quarterly, 29, 349-356. http://dx.doi.org/10.1086/267335

Krugman, H. E (1966). The measurement of advertising involvement. Public Opinion Quarterly, 30(4), 583-596. http://dx.doi.org/10.1086/267457

Landon, S., \& Smith, C. E. (1997). The use of quality and reputation indicators by Consumers: The case of Bordeaux wine. Journal of Consumer Policy, 20(3), 289-323. http://dx.doi.org/10.1023/A:1006830218392

Lawson, R. (1997). Consumer decision making within a goal driven framework. Psychology and Marketing, $14(5)$, 427-449. http://dx.doi.org/10.1002/(SICI)1520-6793(199708)14:5\%3C427::AID-MAR1\%3E3.0.CO;2-A

Miniard, P. W., \& Cohen, J. B. (1983). Modeling personal and normative influences on behaviour. Journal of Consumer Research, 10(2), 169-180. http://dx.doi.org/10.1086/208957

Mitchell, V. W. (1992). Understanding consumers' behaviour: Can perceived risk theory help? Management Decision, 30(3), 26-31. http://dx.doi.org/10.1108/00251749210013050

Mown, J. C. (1988). Beyond consumer decision making. Journal of Consumer Marketing, 5(1), 15-25. http://dx.doi.org/10.1108/eb008214

O’Guinn, T. C., \& Faber, R. J. (1991). Mass communication and consumer behaviour. In T. J. Robertson \& H. H. Kassarjian (Eds.), Handbook of Consumer Behaviour. New Jersey: Prentice Hall.

Olshavsky, R. W., \& Granbois, D. H. (1979). Consumer decision making-fact or fiction? Journal of Consumer Research, 6(2), 93-100. http://dx.doi.org/10.1086/208753

Punj, G. N., \& Stewart, D. W. (1983). An interaction framework of consumer decision making. Journal of Consumer Research, 10(2), 181-196. http://dx.doi.org/10.1086/208958

Shanteau, J. C., Troutman, M., \& Wolf, G. (1975). Commentaries on Bettman, Capon, and Lutz. Journal of Consumer Research, 1(4), 16-19. http://dx.doi.org/10.1086/208603

Shelby, A. N., \& Lamar, N. R. Jr. (1995). Positive emphasis and your attitude: An empirical study. Journal of Business Communication, 32(4), 303-327. http://dx.doi.org/10.1177/002194369503200401

\section{Copyrights}

Copyright for this article is retained by the author, with first publication rights granted to the journal.

This is an open-access article distributed under the terms and conditions of the Creative Commons Attribution license (http://creativecommons.org/licenses/by/4.0/). 